\title{
APLIKASI DATA MINING UNTUK PERBANDINGAN MANAJEMEN LABA TERHADAP TINGKAT RESIKO INVESTASI PADA PERUSAHAAN PERBANKAN DI INDONESIA STOCK EXCHANGE
}

\author{
Andika Prajana ${ }^{1, *}$ \\ 1 UIN Ar-Raniry Banda Aceh
}

\begin{abstract}
Abstrak
The financial report is a means of communicating financial information to parties outside the corporation. The preparation of financial statements, an accrual basis was chosen because it is more rational and fair in reflecting the company's financial condition in real terms, but the other can use the accrual basis to the management to provide more flexibility in choosing accounting methods for not deviate from the rules applicable Financial Accounting Standards. In this study, comparative analysis Persistency Profit Management with Investment Risk level by applying the Application of Data Mining with Rough Set Theory in order to find a pattern or knowledge that can be used as a basis to predict what action will be performed in managing earnings management and banking conditions in company's future.
\end{abstract}

Keywords:

Earnings Management, Risk Level of Investment, Data Mining, Rough Set Theory.

\section{PENDAHULUAN}

Laporan keuangan merupakan sarana pengkomunikasian informasi keuangan kepada pihak-pihak di luar korporasi. Dalam penyusunan laporan keuangan, dasar akrual dipilih karena lebih rasional dan adil dalam mencerminkan kondisi keuangan perusahaan secara riil, namun disisi lain penggunaan dasar akrual dapat memberikan keleluasaan kepada pihak manajemen dalam memilih metode akuntansi selama tidak menyimpang dari aturan Standar Akuntansi Keuangan yang berlaku. Agar dapat melihat adanya peningkatan profit dalam rangka memperluas jasa terutama pemberian macam-macam bentuk kredit ke sektor usaha produktif, maka diperlukan informasi akuntansi secara intern dan analisa laporan keuangan.

Dan akuntansi dapat memberikan informasi tentang kondisi keuangan dari hasil informasi tentang kondisi keuangan dan hasil operasi perusahaan yang nantinya berguna manajemen untuk 1) Mengukur tingkat biaya dari berbagai kegiatan perusahaan, 2) Untuk menentukan atau mengukur efisiensi tiap-tiap bagian proses atau produksi serta untuk menentukan derajat keuntungan yang dapat dicapai oleh perusahaan yang bersangkutan, dan 3) Untuk menilai dan mengukur hasil kerja tiap-tiap individu yang telah diserahi wewenang dan tanggung jawab. Untuk menentukan perlu tidaknya digunakan kebijaksanaan atau prosedur yang baru untuk mencapai hasil yang lebih baik.

Teory Rough set merupakan salah satu teknik yang dirasa cukup efisien untuk Knowledge Discovery in Database (KDD) Proses dan Data mining. Data mining merupakan serangkaian proses untuk menggali nilai tambah berupa pengetahuan yang selama ini tidak diketahui secara manual dari suatu kumpulan data. Teori Rough Set dikembangkan oleh Zdzislaw Pawlak pada tahun 1980-an dan digunakan untuk analisis klasifikasi data dalam bentuk table (Ardedi Frianto Ambarita, 2008; Soft Computing Research Group, UTM, 2001). Teknik ini digunakan untuk menangani masalah Uncertainty, Imprecision dan Vagueness dalam aplikasi Artificial Intelligence (AI). Tujuan dari analisis Rough Set adalah untuk mendapatkan perkiraan rule yang singkat dari suatu tabel. Hasil dari analis Rough Set dapat digunakan dalam proses data mining dan knowledge discovery (Ardedi Frianto Ambarita, 2008).

Data Mining merupakan teknologi baru yang sangat berguna untuk menemukan informasi yang sangat penting dari gudang data. Data Mining mengeksplorasi basis data untuk menemukan pola-pola yang tersembunyi, mencari informasi memprediksi yang mungkin saja terlupakan (Veronika S. Moertini, 2002). Secara umum, teori Rough Set telah digunakan dalam banyak aplikasi seperti medicine, 
pharmacology, business, banking, market research, engineering design, meteorology, vibration analysis, conflict analysis, image processing dan decision analysis, software security and other fields (Soft Computing Research Group, UTM, 2001).

Penelitian ini dilakukan untuk menguji kembali pengaruh manajemen laba terhadap tingkat resiko investasi dengan pengaplikasian data mining. Faktor yang membedakan dengan penelitian sebelumnya, dimana pada periode yang berbeda tersebut keadaan ekonomi yang terjadi juga berbeda dan masih bersifat tradisional sehingga tidak dapat menampung data dalam hal menganalisis, meringkas, dan mengekstrasi pengetahuan data tersebut. Selain itu penelitian ini mengambil sampel pada perusahaan perbankan go public yang terdaftar di Indonesia Stock Exchange/Bursa Efek Indonesia.

\section{METODE PENELITIAN}

Data penelitian ini dikumpulkan dari observasi, buku-buku dan situs yang berhubungan dengan Data Mining khususnya untuk prediksi atau peramalan. Dalam hal ini penulis mengambil database pada perusahaan perbankan yang Go Publik Indonesia.

Sampel yang digunakan dalam penelitian ini adalah perusahaan perbankan yang memiliki kriteria tertentu. Metode pengambilan sampel yang digunakan adalah purposive sampling dimana pengambilan perusahaan sampel dilakukan berdasarkan kriteria sebagai berikut: 1) Perusahaan termasuk perusahaan yang sudah go public terdaftar di IDX/BEI Selama periode 2014 sampai dengan 2016, 2) Perusahaan bergerak dalam bidang perbankan, 3) Data laporan keuangan perusahaan tersedia berturut-turut untuk tahun Pelaporan dari 2014 sampai dengan 2016, 4) Perusahaan sampel tersebut mempublikasikan laporan keuangan auditor dengan menggunakan tahun buku yang berakhir pada tanggal 31 Desember, 5) Data harga saham tersedia selama periode estimasi dan pengamatan.

Data yang digunakan dalam penelitian ini yaitu data sekunder berupa laporan keuangan tahunan yang diterbitkan oleh perusahaan perbankan go public dan dipublikasikan oleh Pusat Referensi Pasar Modal (PRPM) yang terdapat di Bursa Efek Indonesia (BEI). Data yang dipergunakan adalah laporan keuangan selama tahun 2014 sampai 2016 serta data harga saham selama periode pengamatan.

Dari hasil studi literatur yang dilakukan dan data-data yang dikumpulkan, selanjutnya dilakukan tahap analisis. Pada tahap ini, dianalisa lebih mendalam tentang prediksi jumlah perusahaaan perbankan yang go publik di bursa efek Indonesia. Sampai akhir tahun 2016 perusahaan go public yang terdaftar di Bursa Efek Indonesia berjumlah 539 perusahaan, dari keseluruhan perusahaan tersebut diambil sampel sesuai dengan kriteria-kriteria penelitian yang telah ditentukan. Dari perusahaan perbankan yang terdaftar di BEI dari Januari 2014 sampai dengan Desember 2016 maka diperoleh 24 perusahaan perbankan dan memenuhi kriteria-kriteria pemilihan sampel. Pengukuran variabel-variabel dalam penelitian ini menggunakan data laporan keuangan tahunan perusahaan sampel, Indeks Harga Saham Individual (IHSI) dan Indeks Harga Saham Gabungan (IHSG) yang termuat dalam website www.sahamok.com dan www.e-bursa.com

Berdasarkan kriteria-kriteria yang ditentukan dalam penelitian ini, maka tahap pemilihan sampel terlihat pada tabel 1 berikut :

Tabel 1

Tahap Pemilihan Sampel

\begin{tabular}{|c|c|}
\hline $\begin{array}{l}\text { Perusahaan go-publik yang terdaftar di Bursa Efek Jakarta } \\
\text { periode } 2014-2016\end{array}$ & $\begin{array}{r}539 \\
\text { Perusahaan }\end{array}$ \\
\hline Perusahaan Non Perbankan (tidak termasuk sampel) & $\begin{array}{r}419 \\
\text { Perusahaan }\end{array}$ \\
\hline Perusahaan Perbankan \& Lembaga Keuangan lainnya. & $\begin{array}{r}120 \\
\text { Perusahaan } \\
\end{array}$ \\
\hline Perusahaan Perbankan Go-Public & $\begin{array}{r}27 \\
\text { Perusahaan } \\
\end{array}$ \\
\hline $\begin{array}{l}\text { Perusahaan Perbankan Go-Public yang memiliki laporan } \\
\text { keuangan lengkap selama } 3 \text { (tiga) tahun terakhir.(sampel yang } \\
\text { akan digunakan) }\end{array}$ & $\begin{array}{r}24 \\
\text { Perusahaan }\end{array}$ \\
\hline
\end{tabular}

Dari 24 Perusahaan Yang Dijadikan Sampel Penelitian Itu Adalah Sebagai Berikut: PT. BANK BUMI PUTERA.TBK, PT. BANK ARTA NIAGA KENCANA TBK, PT. BANK CENTRAL ASIA TBK, PT. BANK BUANA INDONESIA.TBK, PT. BANK BUKOPIN.TBK, PT. BANK NEGARA INDONESIA TBK, PT. BANK NUSANTARA 
PAHRAYANGAN.TBK, PT. BANK DANAMON INDONESIA.TBK, PT. BANK EKSEKUTIF INTERNASIONAL.TBK, PT. BANK KESAWAN.TBK, PT. BANK MANDIRI.TBK, PT. BANK BUMI ARTA.TBK, PT. BANK NIAGA.TBK, PT. BANK INTERNASIONAL INDONESIA.TBK, PT. BANK PERMATA.TBK, PT. BANK SWADESI.TBK, PT. BANK VICTORIA INTERNASIONAL.TBK, PT. BANK LIPPO.TBK, PT. BANK MAYAPADA INTERNASIONAL.TBK, PT. BANK MEGA.TBK, PT. BANK NISP.TBK, PT. BANK PANIN.TBK, PT. BANK ARTHA GRAHA INTERNASIONAL.TBK, PT. BANK RAKYAT INDONESIA.TBK.

Dari hasil pengumpulan data selanjutnya dilakukan analisis untuk menentukan variabel-variabel yang akan di jadikan input pada Software Rosetta. Dimana variabel-variabel yang dapat diolah adalah Tingkat Manajemen Laba, Persistensi Laba, dan Tingkat Resiko Investasi yang di jadikan patokan prediksinya. Selanjutnya dilakukan Pengolahan Data Dengan Software Rosetta. Pada tahap ini data yang sudah diolah dan variabel yang sudah diperoleh akan di proses dengan menggunakan bantuan Aplikasi Rosetta. Pada tahap evaluasi akhir ini, hasil dari pengolahan data dengan bantuan Software Rosetta untuk memperoleh nilai statistik akan di bandingkan dengan hasil prediksi yang selama ini dilakukan dengan sistem rata-rata (Mean). Sehingga kita dapat menarik suatu kesimpulan terhadap hasil prediksi mana yang lebih mendekati, atau errornya yang lebih kecil.

\section{ANALISIS DAN PEMBAHASAN}

Analisa sistem adalah penguraian dari suatu sistem informasi yang utuh ke dalam bagian-bagian komponen-komponennya dengan maksud untuk mengidentifikasikan dan mengevaluasi permasalahanpermasalahan, hambatan-hambatan yang terjadi dan kebutuhan-kebutuhan yang diharapkan sehingga dapat diusulkan perbaikan. Contoh bentuk laporan yang ada pada saat ini adalah seperti diperlihatkan pada Tabel 2 :

Tabel 2. Bentuk Laporan Keuangan Bank Bumi Putra

\begin{tabular}{lllll}
\hline \multirow{2}{*}{ Komponen } & Tahun & & & Kondisi Bank \\
& $\mathbf{2 0 0 6}$ & $\mathbf{2 0 0 7}$ & $\mathbf{2 0 0 8}$ & \\
\hline \multicolumn{1}{c}{ Kas } & 395.560 & 354.440 & 344.818 & $?$ \\
Bank Indonesia & 385.919 & 343.282 & 332.449 & $?$ \\
Other Bank & 3.172 & 4.406 & 5.330 & $?$ \\
Placement in other Bank & 26.553 & 6.598 & 23.504 & $?$ \\
Hutang Lancar & 947.135 & 972.865 & 1.072 .232 & $?$ \\
Modal Akrual & $(531.491)$ & $(618.579)$ & $(710.899)$ & $?$ \\
Penjualan Periode & 145.778 & 161.776 & 171.171 & $?$ \\
\hline
\end{tabular}

Dari bentuk laporan di atas keputusan yang tepat dan cepat sulit untuk didapatkan, karena tidak lengkapnya bentuk laporan yang diberikan, dan tidak ada variabel-variabel yang mendukung dalam mengambil suatu keputusan. Seperti contohnya pada kolom keterangan, barang hanya dinyatakan rusak saja, tanpa dirinci secara jelas berapa persen tingkat kerusakananya, sehingga keputusan apakah barang tersebut dalam keadaan sehat atau tidak dan sangat sulit untuk ditentukan. Untuk laporan keuangan perusahaan perbankan publik yang terdaftar pada bursa efek Indonesia, laporannya seperti diperlihatkan pada tabel 3, 4, 5,dan 6 berikut:

Tabel 3. Bentuk laporan keuangan PT. BANK ARTA NIAGA KENCANA TBK

\begin{tabular}{llll}
\hline Komponen & Tahun & & \\
& $\mathbf{2 0 0 6}$ & $\mathbf{2 0 0 7}$ & $\mathbf{2 0 0 8}$ \\
\hline Kas & 290.389 & 402.844 & 530.758 \\
Bank Indonesia & 220.594 & 330.080 & 466.864 \\
Other Bank & 38.305 & 36.920 & 33.232 \\
Placement in other Bank & 18.838 & 484.809 & 304.555 \\
Hutang Lancar & 3.013 .099 & 3.533 .739 & 4.112 .943 \\
\hline
\end{tabular}




\begin{tabular}{llll}
\hline Modal Akrual & $(2.735 .362)$ & $(618.579)$ & $(710.899)$ \\
Penjualan Periode & 145.778 & 161.776 & 171.171 \\
Bid & 120 & 120 & 85 \\
Ask & 185 & 185 & 110 \\
\hline
\end{tabular}

Tabel 4 Bentuk laporan keuangan PT. BANK CENTRAL ASIA TBK

\begin{tabular}{llll}
\hline Komponen & Tahun & & \\
& $\mathbf{2 0 0 6}$ & $\mathbf{2 0 0 7}$ & $\mathbf{2 0 0 8}$ \\
\hline Kas & 47.751 .808 & 43.551 .174 & 27.230 .118 \\
Bank Indonesia & 43.944 .805 & 40.374 .524 & 23.224 .571 \\
Other Bank & 314.554 & 226.606 & 206.965 \\
Placement in other Bank & 3.679 .885 & 2.558 .909 & 7.312 .254 \\
Hutang Lancar & 120.663 .866 & 135.242 .451 & 132.335 .335 \\
Modal Akrual & $(72.694 .622)$ & $(92.109 .412)$ & $(101.591 .545)$ \\
Penjualan Periode & 35.033 .912 & 44.230 .512 & 53.339 .314 \\
Bid & 2.875 & 2.875 & 2.600 \\
Ask & 3.650 & 3.650 & 3.375 \\
\hline & & & * dalam juta rupiah
\end{tabular}

Tabel 5 Bentuk laporan keuangan PT. BANK BUANA INDONESIA.TBK

\begin{tabular}{llll}
\hline Komponen & $\begin{array}{l}\text { Tahun } \\
\mathbf{2 0 0 6}\end{array}$ & $\mathbf{2 0 0 7}$ & $\mathbf{2 0 0 8}$ \\
\hline Kas & 808.439 & 1.108 .648 & 1.429 .511 \\
Bank Indonesia & 603.243 & 897.844 & 1.170 .026 \\
Other Bank & 63.850 & 84.288 & 128.926 \\
Placement in other Bank & 643.359 & 534.778 & 1.504 .958 \\
Hutang Lancar & 12.651 .823 & 14.451 .775 & 13.830 .377 \\
Modal Akrual & $(11.341 .371)$ & $(12.934 .865)$ & $(11.026 .467)$ \\
Penjualan Periode & 3.950 .585 & 5.537 .323 & 6.059 .877 \\
Bid & 800 & 800 & 900 \\
Ask & 970 & 970 & 970 \\
\hline & & & * dalam juta rupiah
\end{tabular}

Tabel 6 Bentuk laporan keuangan PT. BANK BUKOPIN.TBK

\begin{tabular}{llll}
\hline Komponen & Tahun & & \\
& $\mathbf{2 0 0 6}$ & $\mathbf{2 0 0 7}$ & $\mathbf{2 0 0 8}$ \\
\hline Kas & 2.368 .172 & 1.222 .238 & 2.826 .460 \\
Bank Indonesia & 2.181 .029 & 1.027 .674 & 2.565 .538 \\
Other Bank & 29.027 & 47.412 & 41.180 \\
Placement in other Bank & 302.118 & 2.216 .600 & 4.056 .464 \\
Hutang Lancar & 16.672 .509 & 17.373 .557 & 23.490 .562 \\
Modal Akrual & $(14.160 .335)$ & $(14.081 .871)$ & $(16.827 .380)$ \\
Penjualan Periode & 2.283 .230 & 2.283 .230 & 2.338 .918 \\
Bid & 410 & 410 & 410 \\
Ask & 420 & 420 & 420 \\
\hline
\end{tabular}

Sebelum memperoleh data laporan keuangan perusahaan perbankan yang sehat, perlu dilakukan pengujian data tersebut diantaranya menganalisa dan membandingkan beberapa komponen-komponen diantaranya: Modified Jones Model dapat mendeteksi manajemen laba lebih baik dibandingkan dengan model-model lainnya sejalan dengan hasil penelitian Dechow et al. (1995). 
Pengukuran Modified Jones Model digunakan untuk menguji Manajemen laba dalam penelitian ini adalah :

\section{Manajemen Laba (ML) $=\{$ Akrual modal kerja (t) / Penjualan periode (t) $\}$ X 100 Akrual modal kerja $\quad=\Delta \mathrm{AL}-\Delta \mathrm{HL}-\Delta$ Kas}

Dimana :

$\Delta \mathrm{AL}=$ Perubahan aktiva lancar pada periode $\mathrm{t}$

$\Delta \mathrm{HL}=$ Perubahan hutang lancar pada periode $\mathrm{t}$

$\Delta$ Kas $=$ Perubahan kas dan ekuivalen kas pada periode $\mathrm{t}$

Maka diperoleh data sebagai berikut :

Nama Bank : Bank Bumi Putra

$$
\begin{aligned}
& \mathrm{ML}_{(2006)}=(-531.491 / 145.778) \times 100 \\
&=-365 \\
& \mathrm{ML}_{(2007)}=(-618.579 / 161.776) \times 100 \\
&= \\
& \operatorname{ML}_{(2008)}=(-382 \\
&=(-710.899 / 171.171) \times 100 \\
&
\end{aligned}
$$

Rata-rata perolehan Manajemen Laba pada bank tersebut adalah:

$$
\begin{aligned}
\Delta \mathrm{ML} & =((-365)+(-382)+(-415)) / 3 \\
& =-387,42
\end{aligned}
$$

Sehingga diperoleh manajemen laba sebagai variable data $\mathrm{X}_{1}$ dalam bentuk Tabel 7 berikut ini

\begin{tabular}{clr}
\hline No & \multicolumn{1}{c}{ NAMA PERUSAHAAN } & \multicolumn{1}{c}{ ML } \\
\hline 1 & PT. BANK BUMI PUTERA.TBK & $-387,42$ \\
2 & PT. BANK ARTA NIAGA KENCANA TBK & $-867,31$ \\
3 & PT. BANK CENTRAL ASIA TBK & $-203,25$ \\
4 & PT. BANK BUANA INDONESIA.TBK & $-234,21$ \\
5 & PT. BANK BUKOPIN.TBK & $-652,13$ \\
6 & PT. BANK NEGARA INDONESIA TBK & $-587,79$ \\
7 & PT. BANK NUSANTARA PAHRAYANGAN.TBK & $-1.521,86$ \\
8 & PT. BANK DANAMON INDONESIA.TBK & $-218,58$ \\
9 & PT. BANK EKSEKUTIF INTERNASIONAL.TBK & $-1.928,43$ \\
10 & PT. BANK KESAWAN.TBK & $-677,97$ \\
11 & PT. BANK MANDIRI.TBK & $-650,35$ \\
12 & PT. BANK BUMI ARTA.TBK & $-53,56$ \\
13 & PT. BANK NIAGA.TBK & $-517,83$ \\
14 & PT. BANK INTERNASIONAL INDONESIA.TBK & $-344,61$ \\
15 & PT. BANK PERMATA.TBK & $-447,67$ \\
16 & PT. BANK SWADESI.TBK & $-231,05$ \\
17 & PT. BANK VICTORIA INTERNASIONAL.TBK & $-1.455,74$ \\
18 & PT. BANK LIPPO.TBK & $-379,64$ \\
19 & PT. BANK MAYAPADA INTERNASIONAL.TBK & $-1.035,95$ \\
20 & PT. BANK MEGA.TBK & $-491,00$ \\
21 & PT. BANK NISP.TBK & $-408,54$ \\
22 & PT. BANK PANIN.TBK & $-308,11$ \\
23 & PT. BANK ARTHA GRAHA INTERNASIONAL.TBK & $-331,03$ \\
24 & PT. BANK RAKYAT INDONESIA.TBK & $-206,18$ \\
\hline & &
\end{tabular}

Untuk mengukur tingkat resiko dari suatu perusahaan perbankan publik yang terdaftar di Bursa Efek Indonesia, kita memerlukan karakteristik perusahaan yang bisa menganalisa adanya faktor-faktor dari tingkat risiko perusahaan tersebut. Karakteristik perusahaan yang menjadi dasar pengujian dalam penelitian ini adalah size. Size diartikan sebagai ukuran aktiva (asset size) yang dipakai sebagai wakil pengukur (proxy) besarnya perusahaan. Sebab dinyatakan demikian adalah karena ditemukannya beberapa perusahaan yang menjadi objek analisis membedakan assetnya terhadap aktivitas perusahaan. 
Jadi besarnya nilai aktiva yang dipakai perusahaan inilah yang akan dioperasionalisasikan dalam analisis praktik manajemen laba.

Secara matematis variabel size diformulasikan sebagai berikut, [Chen and Steiner (1999)]:

SIZE $=$ Ln Total Asset $t_{t}$

Keterangan :

Ln Total asset $=$ natural log total asset perusahaan. berikut:

Sehingga diperoleh nilai Tingkat Risiko sebagai variable data X dalam bentuk Tabel 8 sebagai

\begin{tabular}{clr}
\hline No & \multicolumn{1}{c}{ NAMA PERUSAHAAN } & SIZE \\
\hline 1 & PT. BANK BUMI PUTERA.TBK & 1.116 .138 \\
2 & PT. BANK ARTA NIAGA KENCANA TBK & 3.791 .577 \\
3 & PT. BANK CENTRAL ASIA TBK & 144.410 .562 \\
4 & PT. BANK BUANA INDONESIA.TBK & 15.562 .770 \\
5 & PT. BANK BUKOPIN.TBK & 20.219 .063 \\
6 & PT. BANK NEGARA INDONESIA TBK & 138.627 .068 \\
7 & PT. BANK NUSANTARA PAHRAYANGAN.TBK & 10.082 .853 \\
8 & PT. BANK DANAMON INDONESIA.TBK & 59.768 .734 \\
9 & PT. BANK EKSEKUTIF INTERNASIONAL.TBK & 1.619 .778 \\
10 & PT. BANK KESAWAN.TBK & 1.441 .134 \\
11 & PT. BANK MANDIRI.TBK & 253.658 .243 \\
12 & PT. BANK BUMI ARTA.TBK & 1.411 .096 \\
13 & PT. BANK NIAGA.TBK & 32.042 .501 \\
14 & PT. BANK INTERNASIONAL INDONESIA.TBK & 39.949 .664 \\
15 & PT. BANK PERMATA.TBK & 31.857 .977 \\
16 & PT. BANK SWADESI.TBK & 795.830 \\
17 & PT. BANK VICTORIA INTERNASIONAL.TBK & 1.954 .928 \\
18 & PT. BANK LIPPO.TBK & 27.804 .892 \\
19 & PT. BANK MAYAPADA INTERNASIONAL.TBK & 2.680 .623 \\
20 & PT. BANK MEGA.TBK & 19.210 .018 \\
21 & PT. BANK NISP.TBK & 17.784 .402 \\
22 & PT. BANK PANIN.TBK & 26.745 .501 \\
23 & PT. BANK ARTHA GRAHA INTERNASIONAL.TBK & 6.715 .676 \\
24 & PT. BANK RAKYAT INDONESIA.TBK & 108.175 .159 \\
\hline & &
\end{tabular}

\section{KESIMPULAN}

Atas analisis dan pembahasan yang peneliti lakukan pada sistem pendukung keputusan maka peneliti dapat mengambil keputusan sebagai berikut: 1) Dengan adanya sistem pendukung keputusan dalam pengendalian laporan keuangan dan kondisi dari laporan keuangan perusahaan tersebut, maka proses pengambilan keputusan akan menjadi lebih optimal dan kesalahan dalam porses pengambilan keputusan dapat diminimalkan. 2) Informasi yang dibutuhkan oleh semua pihak yank terdaftar pada perusahaan perbankan yaitu Manajemen, Investor, kreditor dan nasabah dapat tersedia dengan cepat sehingga dapat memberikan kepuasan kepada pihak-pihak tersebut.

Dari hasil pembuatan penelitian ini maka penulis dapat menyampaikan saran-saran: 1) Untuk mendapatkan sebuah keputusan yang cukup tinggi tingkat keakuratannya maka dapat digunakan teknik Artificial Intelligent Rought Set, 2) Untuk mengolah data dengan kapasitas besar dengan teknik artificial intelligence rough set, selain menggunakan software Rosetta dapat juga digunakan software lainnya.

\section{DAFTAR PUSTAKA}

Anggraeni, Fr. 2004. Teori Keagenan dalam Akuntansi Perbankan. Antisipasi, Vol. 8. No. 1 (112 - 126). 
Assih, Prihat. 2004. Pengaruh Set Kesempatan Investasi Terhadap Hubungan Antara Faktor - faktor Motivasional dan Tingkat Manajemen Laba. Disertasi, Yogyakarta. Indonesia : Gadjah Mada University.

Assih, Prihat dan M. Gudono. 2000. Hubungan Tindakan Perataan Laba dengan Reaksi Pasar atas Pengumuman Informasi Laba Perusahaan yang Terdaftar Di Bursa Efek Jakarta. Simposium Nasional Akuntansi II.

Christie, Andrew A. dan Jerold L. Zimmerman. 1994. Efficient and Opportunistic Choices of Accounting Procedures : Corporate Control Contests. The Accounting Review, Vol. 69, No. 4, October, 539 556.

Ciancanelli, Penny and Jose Antonio Reyes Gonzales. 2000. Corporate Governance in Banking A Conceptual Framework. Social Science Research Network.

Cohen, K, Steven Maier, Robert A. Schwartz, David Whitcomb. 1981. Transaction Costs, Order Placement Strategy and Existence of The Bid Ask Spread. Journal of Political Economy 89, 287 - 305.

Coller, M., dan T. Yohn. 1997. Management Forecasts and Information Asymmetry : An Examination of Bid-Ask Spreads. Journal of Accounting Research 35, Autumn, 181-191.

Dechow, Patricia M. et al. 1995. Detecting Earnings Management. The Accounting Review, April Vol. 70 No. 2.

Grady, Paul, 1970 American Institute Of Certified Public Accoutants, p.4, New York.

Greenstein, M., dan H. Sami. 1994. The Impact of The SEC's Segment Disclosure Requirement on Bid-Ask Spreads. Accounting Review 69, Januari, 179-199.

Gujarati, Damodar N. 2003. Basic Econometrics. 4th ed., McGraw - Hill, New York.

Halim, J, Meiden, C dan Tobing. 2005. Pengaruh Manajemen Laba pada Tingkat Pengungkapan Laporan Keuangan pada Perusahaan Manufaktur yang Termasuk dalam Indeks LQ - 45. Simposium Nasional Akuntansi VIII.

Healy, P, K. Palepu. 1999. Discussion of Earnings - Based Bonus Plans and Earnings Management By Business Unit Managers. Journal of Accounting and Economics 26, 143 - 147.

Healy, P, K. Palepu. 2001. Information Asymmetry, Corporate Disclosure, and The Capital Markets : A Review of The Empirical Disclosure Literature. Journal of Accounting and Economics 31.

Krinsky, I., dan J. Lee. 1996. Earnings Announcements and The Components of The Bid-Ask Spread. Journal of Finance 51, September, 1523-1535.

Lev, B. 1988. Toward A Theory of Equitable and Efficient Accounting Policy. The Accounting Review 43, 1 22.

Mewati Ayub." Proses Data Mining dalam Sistem Pembelajaran Berbantuan Komputer ",Jurnal Sistem Informasi Vol. 2 No. 1 Maret 2007 : 21-30

Kusrini, Emha Taufiq, luthfi. (2009). "Algoritma data mining”, Andi Offset, Yogyakarta

Jiawei Han and Micheline Kamber. , (2006). "Data Mining : Concepts and Techniques", Morgan Kaufmann Publishers is an imprint of Elsevier, San Francisco.

Dorian Pyle. (1999). "Data Preparation for Data Mining", Morgan Kaufmann Publishers is an imprint of Elsevier, San Francisco.

Jong, Jek Siang. (2009). "Matematika Diskrit Dan Aplikasinya Pada Ilmu Komputer." Andi Offset, Yogyakarta.

Wijaya, Maman. (2007). "Analisis Hasil Belajar dan Pemanfaatannya” Depdiknas (Science Education Development Centre), Bandung. 